\title{
REVIEW ARTICLE OPEN Integrated computational materials engineering of corrosion resistant alloys
}

\author{
Christopher D. Taylor ${ }^{1,2}$, Pin Lu $^{3}$, James Saal ${ }^{3}$, G. S. Frankel ${ }^{1}$ and J. R. Scully ${ }^{4}$
}

Structure, composition and surface properties dictate corrosion resistance in any given environment. The degrees of freedom in alloy design are too numerous in emerging materials such as high entropy alloys and bulk metallic glasses for the use of highthroughput methods or trial and error. We review three domains of knowledge that can be applied towards the goal of corrosion resistant alloy (CRA) design: (a) the aggregation of knowledge gained through experience in developing CRAs empirically, (b) datadriven approaches that use descriptive metrics for alloy composition optimization, and (c) first-principles models of elementary processes that regulate corrosion informed by theory and inspired by phenomenological models in the literature. A path forward for integrated computational materials engineering (ICME) of CRAs that unites these three knowledge domains is introduced.

npj Materials Degradation (2018)2:6 ; doi:10.1038/s41529-018-0027-4

\section{INTRODUCTION}

Corrosion has a wide impact on society, causing dangerous and expensive damage to structural and functional engineered components, with the cost of corrosion in the US projected to be over $\$ 500$ billion each year. ${ }^{1}$ Understanding and controlling corrosion is necessary for achieving many of the identified engineering grand challenges cited in a recent US National Academy of Engineering study. ${ }^{2}$ For example, the long-term disposal of nuclear waste and the use of interim above- and below-ground storage containers and tanks carry the risk of radionuclide release due to degradation and subsequent loss of integrity of containment barriers. ${ }^{3}$ Safe storage and disposal of nuclear waste is a major societal and technical challenge. Intrinsically corrosion resistant materials, robust to a broad range of potential environments, are needed to provide the exceedingly long required canister lifetimes. Thus, it is of paramount importance to design corrosion resistant alloys (CRAs) having superb intrinsic corrosion resistance by being immune to aggressive forms of corrosion such as pitting. To meet this objective, it is important to develop a scientifically grounded design process for new CRAs.

Achieving CRAs that possess kinetically slow rates of corrosion requires the formation of stable and protective passive surface films possessing an extremely low probability of localized corrosion events. They also rely on successive barriers to the various stages of pitting: pit initiation, stabilization, and propagation. Furthermore, it is desirable to promote mechanisms that ensure rapid repair, repassivation, or other means of corrosion stifling should the passive oxide film be breached chemically or mechanically.

One strategy for the design of CRAs has involved development of homogeneous solid solution alloys with phase and compositional stability, and the minimization of structural and chemical non-uniformities. ${ }^{4}$ Another is the design of multi-phase materials with an optimal balance or combination of alloying elements in each phase ${ }^{5}$ or by providing geometric barriers or chemical obstacles to propagation of corrosion beyond phases depleted in beneficial alloying elements. Major, minor and micro-alloying elements in solid solution are used to enhance corrosion resistance. Major alloying elements include those with sufficient solid state solubility such as $\mathrm{Cr}$ to reach or go beyond a critical threshold required to form a continuous stable passive film over a broad range of electrochemical potentials and $\mathrm{pH}^{6-8}$ or to exceed dealloying parting limit concentrations. Notably, CRAs such as stainless steels containing $\mathrm{Cr}$, and $\mathrm{Mo}$, and nickel-base alloys containing $\mathrm{Cr}$, Mo, and $\mathrm{W}$ are well established ${ }^{9}$. However, alloying elements cannot be added without limit due to the need for phase stability, desirable mechanical properties, minimization of cost, and avoidance of brittle ordered phases. Metallurgical stability over the long term remains a persistent issue for all material classes. As an example, low cost austenitic stainless steel rebar materials that substitute manganese for nickel suffer from reduced $\mathrm{Cr}$ solubility. ${ }^{10}$

Additions of small amounts of molybdenum (1-4 wt\%) and nitrogen $(0.6 \mathrm{wt} . \%)$ to stainless steels, copper ( $\mathrm{min}$. of $0.22 \mathrm{wt} \%)$ to weathering steels, ${ }^{11}$ and arsenic $(\sim 0.02-0.10 \mathrm{wt} . \%)^{12}$ and tin $(\sim 1$ wt.\%) to brass ${ }^{13}$ are potent strategies to improve corrosion resistance with minor or micro-alloying element additions. Although theories exist, the beneficial synergies that arise between alloying elements, particularly between $\mathrm{Cr}$ and $\mathrm{Mo}$, $\mathrm{Ti}-\mathrm{Mo}$, or $\mathrm{Zr}$ and $\mathrm{Nb}$, have yet to be derived from a first-principles basis. That is to say, there is no way a priori to predict such synergies, rather than explaining them in hindsight following empirical observation. In addition, detrimental species are usually controlled or sequestered, such as in low carbon and stabilized grades of stainless steel and contaminant control by rare earth treatment or other practices. ${ }^{14}$ The development of all these alloying additions has often been an empirical effort, resulting from a high degree of either trial and error, laboratory testing, serendipity, incremental advances and field experience. Indeed,

\footnotetext{
'Department of Materials Science and Engineering, The Ohio State University, Columbus, OH 43210, USA; ${ }^{2}$ Materials Technology \& Development, DNV GL USA, Dublin, OH 43017, USA; ${ }^{3}$ QuesTek Innovations LLC, Evanston, IL 60201, USA and ${ }^{4}$ Department of Materials Science and Engineering, University of Virginia, Charlottesville, VA 22901, USA Correspondence: Christopher D. Taylor (taylor.2770@osu.edu)
}

Received: 18 September 2017 Revised: 27 December 2017 Accepted: 4 January 2018

Published online: 20 February 2018 
even in the case of modern approaches applied to enable ICME, integrated time dependent prognosis of processes such as corrosion are a cited weakness. ${ }^{15}$ Implementation of a systematic scientifically driven process would greatly accelerate and improve CRA development.

There are many trade-offs concerning the range of desirable properties for a CRA (cost and processing constraints not being among the least of these) and it is likely that diverse properties cannot be realized simultaneously. As an example, precipitationstrengthened alloys that purposely introduce nanoscale strengthening phases run the risk of solute depletion especially when the heterogeneous nucleation of these strengthening phases occurs at interfaces. ${ }^{16}$ Low-alloy high-strength quenched and tempered steels require carbon for hardness, as well as other elements for hardenability and place phase stability constraints on the passive film former concentrations (e.g., Cr) due to the need to stabilize the high temperature austenite phase required for martensite transformations. ${ }^{17-19}$ Indeed, the metallurgical expertize that has arisen around CRAs is a testament to the ingenuity of the modern era and, in particular, the long term benefits that can be realized by design engineering. However, to overcome this barrier to progress and adopt a more insightful scientific approach, we review some challenges that remain, and assess how Integrated Computational Materials Engineering (ICME) may be applied to corrosion.

\section{CHALLENGES AND OPPORTUNITIES FOR GOING BEYOND STATE OF THE ART}

One of the great challenges is to prioritize desirable features and attributes (i.e., descriptors) that confer corrosion resistance given a complex multi-physics problem that spans many length scales with important processes at each length scale. Attributes that confer good corrosion resistance span across the materials/oxide/ environment interfaces and include point, linear and planar defect states in the material, its oxide, and more. ${ }^{20}$ Computational design of materials using the ICME approach has recently had success in the design of new materials with improved mechanical or electrical properties ${ }^{21}$ but until now has not been applied for designing CRAs. Indeed, the complexity of corrosion phenomena, which depends on both material properties and environmental factors, makes computational design for corrosion a particular challenge.

A crucial missing piece in the computational tools for CRA design is the presence of a unifying model for corrosion with clear, relevant calculable fundamental parameters that can predict the corrosion resistance of an alloy with arbitrary composition and processing history. Likewise, there is no unique metric that can be applied to quantify the corrosion resistance of an alloy from the experimental perspective. Although some quantifiers do exist, such as pitting and repassivation potentials, they are dependent upon the way the experiment is performed and the test environment. Historically, empirical corrosion models are quite limited when applied to novel CRA design. For instance, the most common empirical model, the pitting resistance equivalence number (PREN), was derived strictly by empirical fitting to experimental data for $\mathrm{Fe}-\mathrm{Cr}-\mathrm{Ni}$ alloys, ${ }^{22,23}$ where pitting resistance potency is identified only by adjustments to the regression fit between a desirable corrosion parameter, such as critical pitting potential or critical pitting temperature, and solid solution alloying concentration. PREN contains no science to identify the underlying factors governing the benefits of certain alloying elements, for instance, the Cr-Mo synergy ${ }^{9,24}$. Therefore, the PREN is unable to anticipate favorable properties created by design of CRAs in new compositional spaces that might include elements other than $\mathrm{Cr}$ and $\mathrm{Ni}$ (e.g., HEAs). However, PREN remains a baseline starting point for CRA metrics.
There is clearly a need for an advanced approach to CRA design. In the following section we explore the tremendous opportunity that the ICME paradigm provides to advance CRA design.

\section{THE EMERGING ICME PARADIGM}

The computational modeling of materials has become increasingly powerful, reaching down to the atomistic level and up towards the simulation of full components in an application-realistic environment. ${ }^{25}$ Strategies to harness these modeling techniques for the purpose of corrosion resistance need to integrate these tools together, while maintaining dialog with experimental work and field experience for the purposes of information sharing, verification and validation. ${ }^{26}$ ICME is a modern systems-based approach to designing materials, including both composition and processing parameters, that meet a specific need for performance by linking computational materials models across multiple length scales. ${ }^{27}$ The ICME approach, provided the availability of robust databases, can readily predict many properties for an alloy based on tools such as CALculation of PHAse Diagrams (CALPHAD) $)^{28}$ and Density Functional Theory (DFT). ${ }^{29}$ Thus, it is ideally suited to efficiently and exhaustively examine a myriad of possible CRA compositions, including HEAs, and work toward identifying those with sought-after attributes. The ICME approach has been said to accelerate materials design projects by a factor of at least $2 \times$ with regards to cost and development time. ${ }^{30}$

ICME has been used to design alloys for a variety of demanding applications. ${ }^{31}$ As a specific example, ICME was used to design a high strength stainless steel (Ferrium S53) that targeted highstrength, and corrosion- and stress corrosion cracking (SCC)resistance without requiring traditional cadmium plating.(15) To enable this design, a model for SCC resistance was developed, based on the Rice-Wang mechanism of solute segregation to grain boundaries and composition-dependence of resistance to grain boundary decohesion in the presence of hydrogen(12). Model calibration was performed with DFT data plus experimental measurements of grain boundary chemistry and SCC performance. By combining this cohesion model with thermodynamic phase equilibria models (CALPHAD databases and tools) and models for strength, the composition and heat treatment were optimized to ensure sufficient cohesion enhancing solute at the grain boundary to resist hydrogen embrittlement while also maintaining high strength. While this approach was successful for the development of an alloy resistant to SCC, advances in the design methodology considering more details of the SCC process could lead to increased design efficiency and improved alloys. There is as yet no analogous design methodology for alloys resistant to pitting corrosion.

An analysis of the literature indicates that the ICME approach can be deconstructed into four categories of effort as shown in Table 1.26

The scientific models that describe the underlying phenomenology behind materials performance fall into the second category of effort in Table 1. Science-based modeling techniques that have been applied to elucidate phenomenology related to corrosion include: (a) DFT to compute reaction kinetic parameters such as the nudged elastic band, ${ }^{32}$ dimer methods ${ }^{33}$ and molecular dynamics; ${ }^{34}$ (b) applications of quantum chemical methods to compute solute-surface interactions; ${ }^{35}$ (c) development of ensemble Monte Carlo methods in the quasi-harmonic approximation to produce Gibbs free energies; ${ }^{36}$ (d) computation of diffusion coefficients and kinetics of solid state reactions; ${ }^{37}$ (e) thermodynamic models to infer phase stability, solubility limits and surface segregation; ${ }^{38}$ and ( $f$ ) direct simulation through atomistic modeling of speciation and surface reactions. ${ }^{39}$ The thermodynamic and kinetic parameters obtained from first-principles may be used as inputs to simulations of pit growth using (g) electrochemical models solved via methods such as finite 
Table 1. The four categories of effort in the ICME approach and examples of the kinds of activities that may be performed within each effort

\begin{tabular}{|c|c|c|c|}
\hline No. & Effort Category & Activities & Objectives \\
\hline 2 & Scientific models & $\begin{array}{l}\text { First principles and semi-empirical modeling including } \\
\text { damage mechanics, microstructural modeling, atomistic } \\
\text { simulation, electrochemistry, fluid dynamics, and } \\
\text { thermodynamics. }\end{array}$ & $\begin{array}{l}\text { Foundational understanding for extrapolation beyond } \\
\text { historical and experimental data points, address } \\
\text { unforeseen challenges through mechanistic insights, } \\
\text { and exercise a wider range in possibilities than } \\
\text { accessible experimentally }\end{array}$ \\
\hline 4 & $\begin{array}{l}\text { Uncertainty quantification } \\
\text { and optimal design }\end{array}$ & $\begin{array}{l}\text { Experiments and field data collection, damage } \\
\text { accumulation models, Monte Carlo, Bayesian and } \\
\text { reliability modeling, identification of knowledge gaps. }\end{array}$ & $\begin{array}{l}\text { Highlights strengths and weakness in current scientific } \\
\text { and/or empirical models, targeting areas where more } \\
\text { research is needed to narrow uncertainty, proper } \\
\text { balance of conservatism and risk in materials selection } \\
\text { and lifetime prediction. }\end{array}$ \\
\hline
\end{tabular}

differences, cellular automata or phase-field theory; ${ }^{40-42}$ and (h) models for passive film breakdown and localized corrosion, such as the point-defect model; ${ }^{43}$ and (i) kinetic Monte Carlo simulation of developing corrosion morphologies and alloy systems to identify compositional targets. ${ }^{44}$ Thermodynamic data may be integrated with tools such as CALPHAD ${ }^{45}$ to develop metallurgical databases needed for alloy design. Linking all these approaches together, to provide a complete description of the corrosion process, while technically feasible, is an expensive and complex endeavor requiring multiple teams operating in synergy towards a common design goal. At the same time, developing an understanding of the controlling processes governing corrosion will undoubtedly provide the basis for the next generation of corrosion-resistance metrics.

Towards this end, this review aims to identify and examine the current understanding behind many of the primary attributes that confer superior corrosion resistance. We systematically review features that are desirable in a corrosion resistant alloy based on the accumulated body of experience and theory maturity in corrosion science. Throughout, we review computational-based approaches for alloy design and those areas that we believe are ripe for further development towards providing some new metrics in quantifying alloy corrosion resistance.

\section{FEATURES DESIRABLE IN CRAS}

In this section we review factors that have been associated with durable, high-performing, corrosion resistant alloys, given a broad examination of the development of CRAs in the past. The factors that confer corrosion resistance, and here we consider broadly oxidizing aqueous environments with chloride present, can be divided into key categories:

- Compositional and microstructure control

- Promotion of passivity

- Salt film formation and reactive electrochemistry

- Control of cathodic electron transfer reactions

- Mitigation of stress corrosion cracking (SCC)

These qualities will now be reviewed in turn, with the exception of mitigation of SCC as this topic could entail a review all of its own.

\section{COMPOSITIONAL AND MICROSTRUCTURE CONTROL}

It may be difficult to produce a defect-free oxide and avoid all surface defects that could trigger localized corrosion. This is especially true in classes of alloys where heterogeneity is unavoidable or even metallurgically desirable, as in the case of precipitation age-hardened alloys, dual phase microstructures or quenched and tempered steels. Here the micro-galvanic couples and dealloying properties of intermetallic compounds (IMCs) can be manipulated by micro-alloying. The simplest approach might be to minimize the potential difference between the IMC and the alloy matrix. Adding elements that collect in unavoidable phases and/or render them less potent towards micro-galvanic coupling is desired. ${ }^{46-49}$ Another approach is to engineer inclusions or intermetallics so they are less corrosion prone in isolation. Defect engineering can also be used to minimize size and spacing of intermetallics or inclusions that serve as a sometimes cooperative array of corrosion initiation sites. ${ }^{50-52}$

It is desirable to limit grain boundary segregation or depletion of the alloying elements during heating and in service. Grain boundary and texture engineering may also be beneficial. Favorable grain orientations may be affected by targeted texturing or de-texturing to obtain crystal orientations that passivate or resist halide adsorption better than other orientations. High angle grain boundaries and clean grain boundaries with many special boundaries having low coincident site lattices may be preferred. Theory and modeling using atomistic simulations with many-body potentials have shown how planar defects, such as grain boundaries, can influence transport properties and serve as initiation sites for localized corrosion attack. ${ }^{53}$

To tune composition limits with respect to avoiding dealloying, it is necessary to consider percolation thresholds that control parting limits. Sieradzki and Newman proposed this theory to account for the variation in corrosion resistance according to the concentration of beneficial elements introduced. ${ }^{54}$ Essentially, at a critical composition, clusters of the beneficial element can form connected pathways to act as "corrosion blockers." Various computational models based on kinetic Monte Carlo have been applied to explore how alloy structure and composition influence dealloying. ${ }^{55,56}$

Typical wrought alloys only possess a few of these qualities that are often implemented by intuition or incremental approaches. Sputtered thin films open new possibilities by enabling supersaturated solid solutions beyond equilibrium solubility limits. ${ }^{57}$ Similarly, amorphous glasses ${ }^{58}$ have often been found to offer 


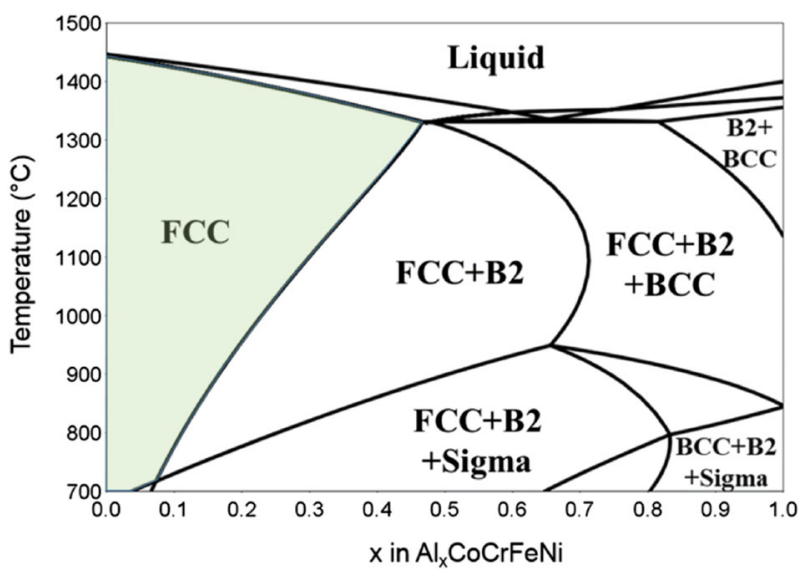

Fig. 1 CALPHAD-predicted phase diagram for an HEA Al $\mathrm{COCrFeNi}$ above $\sim 700^{\circ} \mathrm{C}$. This diagram was calculated using the Thermo-Calc HEA database ${ }^{107}$ and is used to guide design of the processing of an HEA, specifically the compositional boundaries of the single phase FCC HEA (highlighted in green) and the temperatures in which postcast heat treatment (such as homogenization) can be applied (any temperature above the FCC + B2 solvus and below the FCC + Liquid solidus)

superior corrosion resistance. The zenith of corrosion resistance has been seen in metallic glass systems, which exploit corrosion resistance strategies including defect minimization, large beneficial supersaturated alloying concentrations in solid solution that operate alone and produce synergies, as well as various beneficial minor or trace alloying elements. ${ }^{59,60}$ Therefore, they could provide a good model system to test many of the concepts listed above. Many may lack the scalability and versatility in product form; these are recognized engineering shortcomings. HEAs provide another class of compositionally complex systems that form single phase solid solutions, and provide the opportunity to draw benefits from a larger variety of alloy elements often present in nearly equi-atomic proportions. HEAs can be designed to minimize microstructural and compositional heterogeneity, and incorporate large concentrations of beneficial alloying elements in metastable supersaturated single phase solid solutions. Recent work $^{61-63}$ has shown that such HEAs demonstrate good corrosion and oxidation resistance, although many of the mechanistic details are unknown. In Fig. 1 we show how CALPHAD can be used to generate phase diagrams for hypothetical alloys that contain beneficial elements and to determine compositions that possess homogeneous single-phase regions. Phase diagrams of this nature can be used not only to determine the composition limits but to guide the heat treatments necessary to produce single phase HEAs.

\section{PROMOTION OF PASSIVITY}

Whereas the identity, composition and physical attributes of the metal are the foundations of corrosion resistance, the passive film on a CRA is the first point of exposure between the metal and its environment. The weakest links in the oxide film, apart from the heterogeneities described above, are the point defects and grain boundaries that enable transport and provide pathways between the environment and the underlying metal, and function as active sites for passive film breakdown. For this reason, the identity of the oxide and the processes and individual events that lead to oxide defect formation via environment interaction is of paramount importance. However, when local passive film breakdown occurs at such defects, and a pit nucleates, the interactions between the local chemistry and the metal surface then determine if a stable pit can continue to grow. If the criteria for acid or chloride induced pit stabilization ${ }^{64}$ are not satisfied, then repassivation will occur and the metal maintains corrosion resistance.

Robust passive oxide films must possess a broad range of thermodynamic stability in harsh environments; the starting point is usually expressed in terms of electrochemical potential / $\mathrm{pH}$ stability diagrams. The advent of ICME tools brings about the possibility for making fast computational predictions of stability regions of oxides in the potential-pH domain for arbitrary metals and alloys. Figure 2 shows a CALPHAD-predicted Potential- $\mathrm{pH}$ Pourbaix diagram for Inconel 600 , and illustrates the regions of preferred thermodynamic stability for the NiCrFe alloy phase, aqueous phases (i.e., corrosion), and various oxides including $\mathrm{Cr}_{2} \mathrm{O}_{3}, \mathrm{FeCr}_{2} \mathrm{O}_{4}, \mathrm{Ni}, \mathrm{Fe}_{2} \mathrm{O}_{3}$, and $\mathrm{NiFe}_{2} \mathrm{O}_{4}$, as well as the oxy hydroxide $\mathrm{NiOOH}$. The diagram generated by CALPHAD has considerable overlap with those developed by Beverskog and Puigdomenech. $^{65}$

Kinetically spontaneous passivation is one of the first requirements after thermodynamic stability and this calls for a low primary passive potential and fast hydrogen evolution reaction rate, which enables easy natural attainment of pit bottom potential above the primary passivation potential in strong reducing acids such as at pits and other harsh environments. The formation of multi-component spinels or high entropy oxides existing as a single homogeneous phase may further enhance passivity especially if they resist $\mathrm{Cl}^{-}$adsorption, and have formation rates greater than chemical dissolution rates in harsh environments. Beneficial passive films are typically thin semiconducting oxides, oxy-hydroxides or hydroxides. Growth of these passive films may be governed by cation or anion ejection, or ionic transport contingent on mobile point defects. These ejection and transport processes will be subject to the high electric fields across the materials/environment interface. They should possess low electronic conductivity, as well as few reactive sites, which enables suppression of electron transfer reactions that drive corrosion. ${ }^{66}$ They typically contain a critical amount of a beneficial alloying element in homogeneous solid solution that is readily enriched to form the desired passive film and in amounts exceeding the thresholds for passivation, and that promote the formation of continuous conformal films. ${ }^{67}$

According to one theory, the high concentration of $\mathrm{Cr}$ in the passive films on Fe-based alloys, ${ }^{68}$ even those with a modest $\mathrm{Cr}$ content of only $15 \%$, is achieved through a combination of high $\mathrm{Fe}^{2+}$ and $\mathrm{Fe}^{3+}$ dissolution rates from the outer layer of the passive film, fast transport of $\mathrm{Fe}^{2+}$ and $\mathrm{Fe}^{3+}$ cations combined with slow transport of $\mathrm{Cr}^{3+}$ through the oxide, and negligible chemical dissolution of $\mathrm{Cr}^{3+}{ }^{69}$ High ionic defect formation energies and barriers to vacancy mediated point defect migration are desired in this context. In such a way, $\mathrm{Cr}$ is enriched greatly in the passive film despite possessing only a modestly greater thermodynamic stability in the oxide phase compared to Fe.

The oxide may be furthered engineered by manipulating the film through addition of dopants (i.e., minor elements), or by using other routes to control the functional properties of these semiconducting oxide films such as tuning the surface composition to favor adsorption of certain anions, ${ }^{70,71}$ changing the number of charge carriers and semi-conducting nature of oxide films to suppress electron transfer reactions, ${ }^{72,73}$ or changing the isoelectric point or $\mathrm{pH}$ of zero charge of surface oxides. ${ }^{74-76}$

Shibata considered that the resistance of an oxide film to localized corrosion would be related to the hardness/softness properties of the surface complexes that can form. ${ }^{77}$ Hardness and softness are properties that describe the tendency of a chemical system to exchange electrons. Soft systems are readily polarizable, whereas hard systems undergo sharp (stepwise) changes in electronic state. For this reason, soft-anions and soft-cations tend to pair up with one another, as do hard anions and hard cations ("like attracts like"). Shibata's model rationalized SCC behavior in 


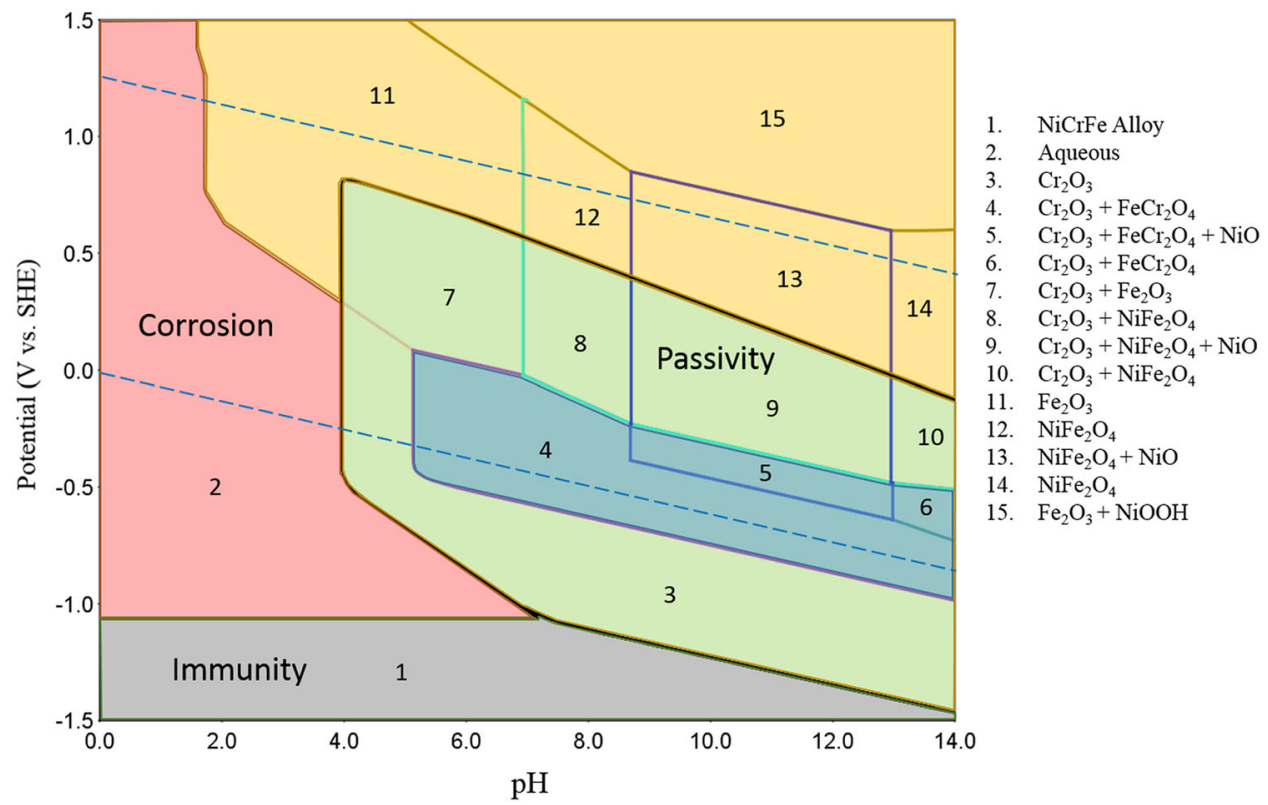

Fig. 2 CALPHAD-predicted Potential-pH Pourbaix diagram for Inconel 600. The composition used for calculation is $76.5 \mathrm{Ni}-15.5 \mathrm{Cr}-8 \mathrm{Fe}$ (wt\%). Alloying elements $\mathrm{Mn}, \mathrm{Cu}, \mathrm{Si}$, and $\mathrm{C}$ are ignored here due to their incidental concentrations $(<1 \mathrm{wt} \%)$. The diagram was calculated in ThermoCalc under the conditions of $25^{\circ} \mathrm{C}, 1 \mathrm{~atm}, 1 \mathrm{~kg} \mathrm{H} \mathrm{H}_{2}, 0.6 \mathrm{M} \mathrm{NaCl}$, total metal ion concentration of $10^{-4} \mathrm{M}$ with the concentration of $\mathrm{Ni}$, $\mathrm{Cr}$, and Fe ions being $7.394 \times 10^{-5} \mathrm{M}, 1.76 \times 10^{-5} \mathrm{M}$, and $8.46 \times 10^{-6} \mathrm{M}$. The databases employed were TCAQ3, SSUB3, and SSOL4. TCAQ3 contains most of the aqueous oxidized species for $\mathrm{Ni}, \mathrm{Cr}$, and $\mathrm{Fe}\left(\right.$ e.g., $\mathrm{Ni}^{2+}, \mathrm{Ni}(\mathrm{OH})_{3}{ }^{-}, \mathrm{Cr}^{2+}, \mathrm{Cr}^{3+}, \mathrm{CrO}_{4}{ }^{2-}, \mathrm{Fe}^{2+}, \mathrm{Fe}^{3+}$, etc.); SSUB3 includes all the three elements as single oxides/hydroxides and the Fe-Cr, Ni-Fe, Cr-Ni spinels; the FCC phase in the appended SSOL4 database is included to describe the Inconel 600 matrix. Gas phases in SSUB3 along with $\mathrm{H}_{2}$ and $\mathrm{O}_{2}$ in TCAQ3 are excluded from the calculation to reveal the complete stability regions of oxide phases, which otherwise would be overlaid and blocked by gas phase regions. The water stability region boundary lines were added back into the diagram afterwards manually (blue dashed lines). Various regions are highlighted in the diagram: the gray region is the immunity region where oxidation of metals is predicted to occur; the red region indicates where aqueous phase is stable (at least one of the aqueous metal species is stable, but not necessarily all alloying elements are aqueous) and corrosion might occur; the blue, green, and yellow regions represent where protective oxides are stable and passivity may register. More specifically, the blue region is where Fe-Cr spinel is stable, the green region is where $\mathrm{Cr}_{2} \mathrm{O}_{3}$ is stable, and the yellow region is where other oxides are stable

terms of how the hardness of cations and anions can inhibit or accelerate SCC by interacting with bound water at the surface of the passive film. While there remain some aspects of this theory that need further quantification, the idea of quantifying environmental contributions to corrosion through hardness and softness metrics may have some utility.

Macdonald's point defect model has been applied to predict the steady-state properties of the passive film according to the film growth kinetics associated with the migration of point defects (e.g., cation vacancies, cation interstitials, and anion vacancies) through the film and their creation/annihilation at the metal/oxide and oxide/environment interfaces. ${ }^{43}$ The model was used to describe passivity breakdown characteristics, pit nucleation and transpassive dissolution. Accordingly, designing for passivity may involve tailoring the point defect transport and creation/annihilation properties. ${ }^{78}$

In summary, useful properties for the passive oxide film are to:

- contain elements that enable fast repassivation rate at scratches and flaws (e.g., good self-healing abilities)

- spontaneously passivate by having a low formation potential and high rate of hydrogen evolution to counteract acidification

- promote beneficial synergy among alloying elements

- exhibit desirable mechanical properties of oxides including good ductility, high fracture stress, low interfacial stresses between oxides and substrates, resistance to oxide cracking and spallation

- possess high adherence to the metal surface to resist chemical and mechanical delamination. ${ }^{79}$
- have electronic properties that mediate the population of point-defects ${ }^{80}$ and suppress electron transfer ${ }^{81}$

\section{SALT FILMS AND REACTIVE METAL ELECTROCHEMISTRY}

Once a passive film has broken down, the applied potential is often far from equilibrium, so that rapid metal dissolution occurs. The bare alloy will ideally have a dissolution rate limited by alloying in the active state, resist halide adsorption, and enrich alloying elements that reduce corrosion or collect at low coordination dissolution sites but not those that increase dissolution such as metalloid elements. ${ }^{82}$ Thermodynamically, it is desirable for non-protective salt films to be less stable than passivating oxide films. Therefore, certain elements in solid solution will ideally function as dissolution blockers. ${ }^{83}$ Metalmetal (M-M) binary and multi-element interactions at surfaces can create conditions that are unfavorable to bond cleavage and solvation. Exposed metallic surfaces in nascent pits should have low dissolution rates in acids to thwart attempts to create and maintain a stable corrosion environment. Lastly, elements that dissolve in active pits should ideally not be not strongly hydrolyzed, since this would lower the $\mathrm{pH}$, creating an even more aggressive corrosion environment.

After a passive film breakdown event, electrochemical and chemical reactions occur at the nucleating pit surface such as metal dissolution, hydrolysis, acidification, $\mathrm{Cl}^{-}$migration into pits and the competition between salt film and oxide stability. Such reactions become the key technical issues of importance considering rapid dissolution of the metal alloy in competition 


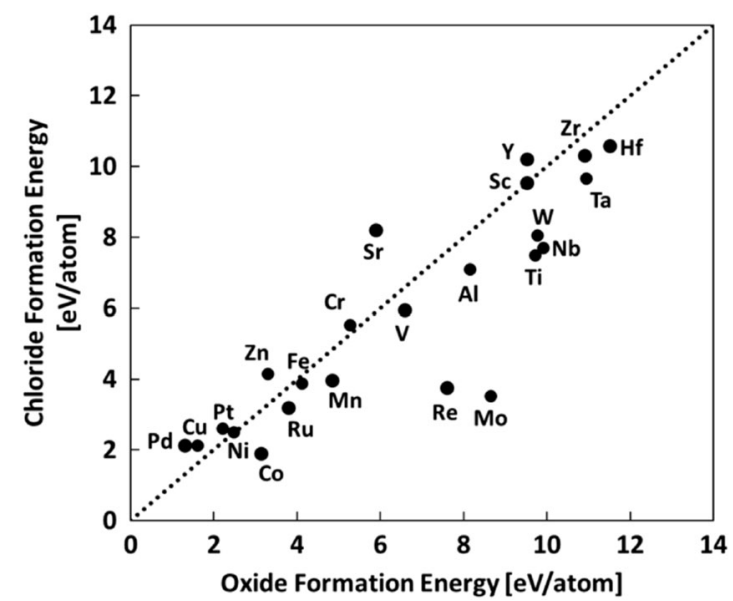

Fig. 3 Comparison between metal-rich oxide and chloride DFTpredicted formation energies for different metals

with repassivation by oxide formation. ${ }^{64,84}$ Given the high rates of ionic phase diffusion away from small localized corrosion sites, propagation (i.e., pit or crevice growth) may also be stifled by the inability of the coupled cathode to polarize the local corrosion site to high enough potentials to achieve the dissolution rate required to maintain the aggressive local environment. ${ }^{85,86}$ Therefore, coupled oxygen reduction reaction (ORR) kinetics are important.

Anderko, Sridhar and Dunn, in a series of papers, ${ }^{87-89}$ laid out a method for predicting the repassivation potential of alloys, given a database of adsorption parameters and activation energies for the processes of dissolution (corrosion) and repasssivation (nucleation of oxides). The model was made applicable to scenarios in which a salt-film (halide) may or may not be present, and has been extended to sour water environments (containing $\mathrm{H}_{2} \mathrm{~S}$ ).

Following similar reasoning, one could conceivably construct plots that quantify environmental effects that are also known to contribute to corrosion, for instance, resistance to a chloride environment. Figure 3 is a cross plot of chloride formation energies of various elements versus oxide formation energies. It provides insight into the effects of alloying elements on localized corrosion in chloride-containing environments. The formation energies are taken from the Open Quantum Materials Database (OQMD), with the most metal-rich stable compound for each metal ion selected. ${ }^{90}$ Although there is a clear linear correlation between metal oxide formation energy and metal chloride formation energy for most elements, Mo is a notable exception, where the oxide is more stable than the chloride. This distinction could be related to the observed extraordinary effect of Mo on boosting pitting resistance of alloys. Other outliers such as $\mathrm{Re}, \mathrm{Nb}$, $\mathrm{Ti}$, and $\mathrm{S}$ may warrant further study. Other parameters that could be explored in a similar way include the metal hydrogen bond strength. In the field of catalysis, this parameter has been shown to have a 'volcano relationship' with the hydrogen evolution reaction (HER) exchange current density, and thus has been used for optimization of electrocatalytic alloy material compositions. ${ }^{91,92}$ To optimize corrosion resistance, it would be desirable to seek combinations that minimize the electrochemical activities towards processes such as oxygen reduction as discussed below. In contrast, high local hydrogen production rates in pits generate $\mathrm{OH}^{-}$, due to the consumption of $\mathrm{H}^{+}$in the HER. This reaction, therefore, counterbalances acidity due to cation hydrolysis. This property may be optimized by regulating the $\mathrm{M}-\mathrm{H}$ bond strength to obtain a fast HER rate. Local cathodes are known to mitigate the $\mathrm{pH}$ drop due to hydrolysis ${ }^{93,94}$ and the $\mathrm{pH}$ drop in pits is mitigated by the proportion of local cathode reaction. The HER exchange current density of a metal is directly related to its work function ${ }^{91}$ and can be accessed through DFT modeling. Therefore, fast HER reactions aid in repassivation of pits. Moreover, fast proton reduction helps passivate alloys in strong reducing acids.

First-principles (atomistic and quantum chemical) methods have been applied to study the metal/electrolyte environment, thereby making direct 'ab initio' prediction of relevant factors such as adsorption energies, reaction activation energies, and to study surface processes such as diffusion and dissolution. The latest methods include directly the effects of solvation and an electrochemical interface. ${ }^{95,96}$ Materials that are resilient to corrosion will have high activation barriers to dissolution, but on the other hand readily repassivate upon damage initiation. ${ }^{97}$ As these methods mature, it will be possible to simulate the processes of surface oxidation and salt-film formation, and to determine the rate-limiting steps to such processes as a function of the materials composition and environment. Through such studies, it will be possible to identify key descriptors that can be used as metrics to screen candidate materials and complex compositions.

\section{CONTROL OF CATHODIC REACTIONS SUCH AS ORR}

Corrosion involves a coupling between the anodic dissolution reactions and the cathodic reactions that accept the electrons produced through the metal dissolution electrochemistry. For this reason, design strategies should also consider ways to limit fast cathodic reactions outside of pits that may support pitting. ${ }^{66}$ The use of volcano curves has been one approach to optimizing materials compositions for optimal catalytic activity. Engineering alloying elements and oxides that perform the opposite function and possess high overpotentials for the oxidizing cathodic reactions are desirable assuming the presence of protective oxides spontaneously formed on cathode sites supporting pits. In essence, an alloy surface may be designed by ternary or higher combinations of oxide elements to lower the ORR exchange current density or poison this reaction, which is the opposite of the typical goal for fuel cell binary or ternary metal catalysts. ${ }^{70,71}$ The ORR reaction rate can be regulated by selection of elements with the $\mathrm{M}-\mathrm{O}$ adsorption strength selected for a slow reaction rate.

\section{DEVELOPING NEW METRICS FOR CRA DESIGN}

The challenge remains to develop a better approach than PREN based on scientific principles that can link atomistic, molecular and microstructure scale attributes to corrosion engineering properties. Already introduced in the preceding section, Marcus developed a conceptual model to explain (and then forecast) the ability of certain alloying elements to impart localized corrosion resistance. ${ }^{83}$ The approach presented is essentially a twodimensional metric that characterizes the roles of alloying elements in the corrosion resistance of alloys based on the $M-M$ bond energy and heat of adsorption of oxygen (i.e., metal-oxygen bond strength) as a first step in first principles based alloy design for corrosion. A cross plot of these thermodynamic parameters for twelve metals was presented and two corrosion-resistant alloying groups were identified: passivity promoters and dissolution moderators (or blockers). The approach is very similar to the methodology developed by Ashby that uses two-dimensional plots of materials properties to guide materials selection. ${ }^{98}$

Marcus' analysis revealed that passivity promoters include $\mathrm{Al}, \mathrm{Ti}$, and $\mathrm{Cr}$, and the identified dissolution moderators are $\mathrm{Mo}, \mathrm{Nb}, \mathrm{Ta}$, and $\mathrm{W}$. The grouping of passivity promoters is based on the notion that metals that adsorb oxygen (or $\mathrm{OH}$ ) strongly, and whose $\mathrm{M}-\mathrm{M}$ bond is easily broken, will be favorable for formation and growth of a passive film. Similarly, metals are identified as dissolution moderators if they exhibit strong $M-M$ bonds, which make it energetically difficult to separate them (dissolve) from the matrix under conditions when the oxide film is absent (active corrosion) 


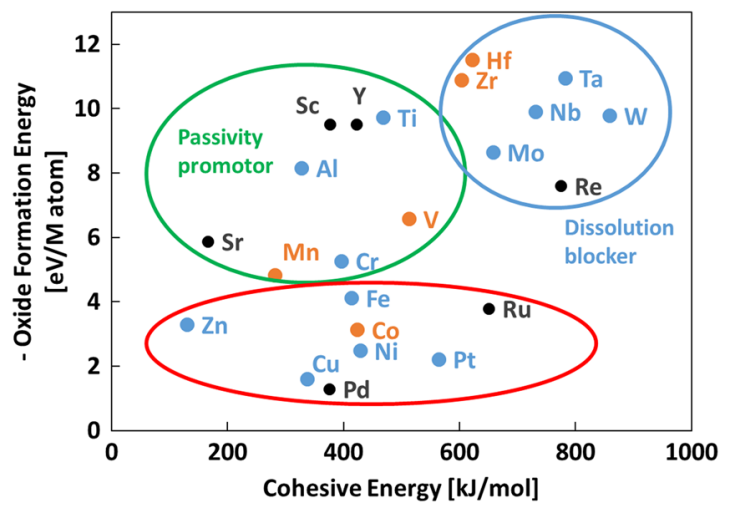

Fig. 4 Cohesive energy as a proxy descriptor for metal dissolution resistance, plotted against oxide formation energy as a proxy for ease of passivation. The blue points are elements from Marcus' original plot, from which this analysis was inspired ${ }^{82}$, orange are elements included in the Thermo-Calc HEA database (TCHEA), ${ }^{107}$ and black are additional elements. Regions containing similar elements are circled (passivity promoters in green, dissolution blockers/moderators in blue, and all other elements in red)

or during passivation where a low critical current density is desired. To expand the element set to include CRA-forming elements present in Thermo-Calc's HEA CALPHAD database, oxide formation energies from the $\mathrm{OQMD}^{21}$ and reported experimental cohesive energies ${ }^{99}$ were used as indicators for the $\mathrm{M}-\mathrm{O}$ and $\mathrm{M}-\mathrm{M}$ bond strengths, respectively.

Most elements in the original Marcus plot [blue data points in Fig. 4] are also included in the Thermo-Calc HEA database. Expanding the adapted Marcus plot to include additional elements that might confer corrosion resistance has led to identification of other metals that meet these criteria. Most notably, elements in the Thermo-Calc HEA database [orange data points in Fig. 4] such as $\mathrm{V}, \mathrm{Zr}$, and $\mathrm{Hf}$ reside within or between the regions of passivity promoters and dissolution moderators. Assuming the general Marcus rule of corrosion resistant alloying metals holds for these elements, it is suggested that they might be incorporated in the CRA chemistry to improve corrosion resistance. Additional metals not included in the original paper or the HEA database [black data points in Fig. 4] also land in the corrosion-resistant categories: Sc, Y, and Re. The advent of readily available online materials databases such as OQMD and Materials Project ${ }^{100}$ has proven useful for data searching and compilation, which will lend itself to developing an improved PREN-like model.

Using E-pH diagrams, thermodynamically favorable oxides may be predicted for a given alloy composition and the estimated stability range. ${ }^{101}$ Similar advancements to the $M-M$ bonding principle may be applied to the $\mathrm{M}-\mathrm{O}$ concept to forecast strong $\mathrm{M}-\mathrm{O}$ combinations that are capable of forming a surface likely to be a strong oxide former. The goal of alloy design would be to first alloy and then enrich on the surface the desired alloying elements that are beneficial towards corrosion. The oxides selected might be those with high stability against forming $\mathrm{M}-\mathrm{Cl}$ complexes, high defect formation energies, weak $\mathrm{Cl}^{-}$adsorption and limited lowering of surface energy with $\mathrm{Cl}^{-}$adsorption. This gives the critical threshold alloying content needed for passivation. Whether a given element enriches in the surface passive film and to what extent is the subsequent challenge. The critical alloying content of $\mathrm{Cr}$ has been predicted by Kirchheim, Marcus and Gimel and others. $^{68,102-104}$ Example plots are shown in Fig. 4 where $\mathrm{Cr}$ enrichment in the outer layer of the surface of a $\mathrm{Fe}-\mathrm{Cr}$ alloy expressed at $\mathrm{X}_{\mathrm{Cr} \text {, e }}$ is predicted as a function of the difference in dissolution rates of the two elements at the oxide solution interface and the bulk $\mathrm{Cr}$ content in the alloy, $\mathrm{X}_{\mathrm{Cr}, \mathrm{a}}$. This concept is an important consideration for alloy design: Certain beneficial alloying element may be selected based on E-pH and $\mathrm{M}-\mathrm{O}$ or $\mathrm{MO}-\mathrm{Cl}^{-}$considerations, and then the critical surface enrichment content for that element will need to be determined.

Moving forward with a corrosion resistant alloy metric that improves on PREN, however, will require understanding of how variations in the proportions of these alloying elements, sought for the scientific reasons elucidated above, produce quantifiable gains in the resistance of the material towards corrosion expressed in engineering terms such as the pitting potential. From a general standpoint, a numerical, computer-driven optimization process requires an objective function, say a corrosion resistance factor $\mathrm{CRF}$, against which variables, in this case, values for the alloy composition and the subsequent processing parameters, are varied to find a maximum or minimum. With regards to what is currently known about corrosion resistant alloys, we propose a series of metrics that need to be collectively optimized. These could be conceivably based around the six categories discussed above. These are passivity promotion, microstructure control, halide resistance, anodic dissolution, limited cathodic ORR reactivity, and fast HER kinetics. These six $\mathrm{CRF}_{\mathrm{i}}$ parameters 1-6, might be summed in some linear or non-linear weighted function $f\left(\mathrm{CRF}_{\mathrm{i}}\right)$ to produce an overall corrosion resistance metric, $\mathrm{CRF}_{\text {tot. }}$.

$\mathrm{CRF}_{\text {tot }}=\Sigma_{\mathrm{i}=1 . .6} \mathrm{f}\left(\mathrm{CRF}_{\mathrm{i}}\right)$

$\mathrm{CRF}_{1}$ : Metric expressing potential for passivity promotion

CRF2: Metric expressing microstructural stability

CRF3: Metric expressing resistance to halide induced corrosion effects

CRF4: Metric expressing intrinsic resistance to metal anodic dissolution

CRF5: Metric expressing potential for low cathodic ORR current

CRF6: Metric expressing hydrogen tolerance

As highlighted above, there are two routes to construct such metrics. The first method is purely data driven, and involves searching for correlations between descriptive variables between alloy attributes discussed above and a quantifiable performance index. In the emerging world of materials informatics, it is possible to use machine learning to find hitherto unexpected correlations emerging from a widespread database of materials descriptors. For this reason, compilation of a database of electrochemical parameters, such as pitting potential, repassivation potential, corrosion potential and corrosion current, critical pitting temperature, transpassive breakdown potentials, capacitance and polarization resistance, as well as microstructural features such as oxide thickness measurements, homogeneity, second phase and intermetallic particle distributions, etc. as a function of material composition, heat treatment and environmental exposure would be immensely helpful in driving a data-centric approach to materials design. The challenge with this approach is that much new experimental lab-bench work would need to be provided to build statistically accurate models, and when moving into new design space, the data may simply not be available. Hence, a scientifically authenticated approach also needs to be adopted.

The second methodology, therefore, retains a role for scientific modeling of factors highlighted above based on first-principles. Using the scientific understanding of corrosion processes as described in the preceding section, one can in the future construct models for the corrosion mechanisms that are relevant to each of the potential descriptors. For passivity promotion, theory-based computational approaches might focus on $\mathrm{M}-\mathrm{O}$ bond strength, halide adsorption, and beneficial element enrichment for microstructure control. It might center upon thermodynamic descriptors of phase stability, and for halide resistance it could be the ratio of chloride and oxide formation energies. This approach could be even further expanded towards understanding and developing key phenomenological models that capture the individual processes that make up the local corrosion of CRAs such as film nucleation, growth, film alteration in the presence of corrosive 


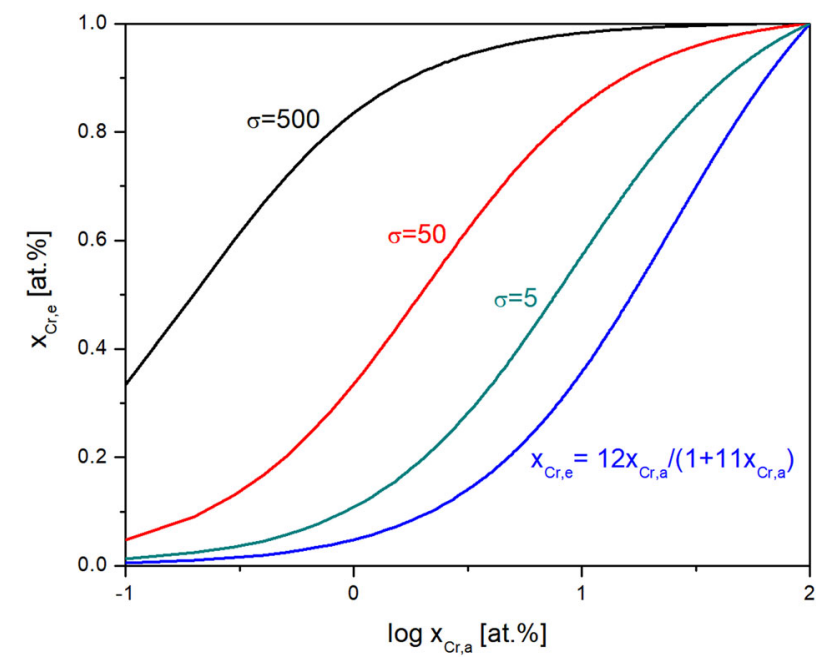

Fig. 5 Estimation of $\mathrm{Cr}$ surface enrichment fraction, $\mathrm{X}_{\mathrm{Cr} \text {,e }}$ on an $\mathrm{Fe}-\mathrm{Cr}$ alloy as a function of the $\mathrm{Cr}$ content of the alloy expressed as atomic $\% \mathrm{X}_{\mathrm{Cr}, \mathrm{a}} \sigma \mathrm{\sigma}$ is either the ratio of $\mathrm{Fe}$ to $\mathrm{Cr}$ dissolution rates in the passive range in $\mathrm{H}_{2} \mathrm{SO}_{4}$, or the ratio of cation transport rates for migration controlled collection. $\sigma=500$ was found for $\mathrm{Fe}-\mathrm{Cr}$ alloys in sulfuric acid. $\sigma$ was 7 when $\mathrm{Cr}$ and $\mathrm{Fe}$ cation transport were dominate factors. Using 5 the critical alloying content is great than 10 at. $\%{ }^{68}$. The black, red, green curves are from the Kirchhiem model. Using the Marcus and Gimal approach ${ }^{102}$ the critical Cr content is 15 at. \% $\mathrm{Cr}$ (Blue)

chemical species, the development of an instability and trigger for initiation, followed by stabilization, and pit propagation. ${ }^{105}$ Each stage should be considered separately and then considered in combination utilizing a multi-physics and multi-length scale model. Critical processes could be identified and considered in alloy design. Situations may exist where one process dominates compared to others. ${ }^{106}$ Incorporating this approach alongside and interacting with the data-driven approach described above can provide powerful gains as a stepping stone towards a full multiphysics model that captures all the critical processes.

\section{CONCLUSIONS}

In this paper, we have reviewed three domains of knowledge that can be applied towards the goal of CRA design: (a) The aggregation of knowledge gained through experience in developing CRAs primarily from a trial-and-error perspective, (b) Datadriven approaches that seek to find descriptive metrics that allow alloy composition optimization, and (c) science-based firstprinciples models inspired by phenomenological models in the literature. The ICME paradigm can be used to unite these three knowledge domains towards deriving an overall framework for predicting corrosion resistance, given a CRA composition. Throughout the discussion we have used the example of HEAs as a rising class of CRAs where there is a need for ICME to guide the alloy development in the complex multi-dimensional design space. Facilitating the development of new CRAs from materials classes such as HEAs will be critical to address the critical technical and societal challenges we face, such as the safe storage and longterm disposal of radioactive waste. Finally, the approach we have expressed in this paper could be applied across differential materials categories including ceramics and glasses.

\section{ACKNOWLEDGEMENTS}

This work was supported as part of the Center for Performance and Design of Nuclear Waste Forms and Containers, an Energy Frontier Research Center funded by the U.S. Department of Energy, Office of Science, Basic Energy Sciences under Award \# DE-
SC0016584. Kathleen Quiambao is gratefully acknowledged for the creation of Fig. 5. The authors thank Drs. Narasi Sridhar, Ron Latanision, and Prasanna Balachandran, and Mr. Sirui Li for reviewing the paper and providing numerous helpful suggestions. Dr. Huibin $\mathrm{Ke}$ is gratefully acknowledged for her assistance in reviewing and preparing the manuscript for final publication.

\section{AUTHOR CONTRIBUTIONS}

All authors contributed to the development and discussion of the ideas presented within this paper. All authors wrote portions of the manuscript, and revised and approved the final manuscript.

\section{ADDITIONAL INFORMATION}

Competing interests: The authors declare no competing financial interests.

Publisher's note: Springer Nature remains neutral with regard to jurisdictional claims in published maps and institutional affiliations.

\section{REFERENCES}

1. Koch, G. H., Thompson, N. G., Brongers, M. P. H. \& Payer, J. H. Cost of Corrosion Study. https://www.nace.org/Publications/Cost-of-Corrosion-Study/ (2002).

2. Perry, W. et al. NAS Grand Challenges for Engineering. (National Academy Press, 2008).

3. Enos, D. G. et al. UFD Expert Panel on Chloride Induced Stress Corrosion Cracking of Interim Storage Containers for Spent Nuclear Fuel. Report No. SAND2017-0414 (Sandia National Laboratory, 2017).

4. Qiu, Y., Thomas, S., Gibson, M. A., Fraser, H. L. \& Birbilis, N. Corrosion of high entropy alloys. npj Mat. Deg 1, 15 (2017).

5. Lucente, A. M. \& Scully, J. R. Localized corrosion of al-based amorphous nanocrystalline alloys with solute lean nanocrystals: pit stabilization. J. Electrochem. Soc. 155, C234-C242 (2008).

6. Sieradzki, K. \& Newman, R. A percolation model for passivation in stainless steels. J. Electrochem. Soc. 133, 1979-1980 (1986).

7. McCafferty, E. Graph theory and the passivity of iron-chromium binary alloys. Electrochem. Solid-State Lett. 3, 28-30 (2000).

8. Herbsleb, G. \& Schwenk, W. Electrochemical investigations of pitting corrosion. Corros. Sci. 13, 739-746 (1973).

9. Sedriks, A. J. Corrosion of stainless steel, Vol. 2 (1996).

10. Presuel-Moreno, F., Scully, J. R. \& Sharp, S. R. Literature review of commercially available alloys that have potential as low-cost, corrosion-resistant concrete reinforcement. Corrosion 66, 86001-86013 (2010).

11. Buck, D. M. Influence of very low percentage of copper in retarding the corrosion of steel. Proc. Am. Soc. Test. Mater. 19, 224-237 (1919).

12. Pryor, M. J. \& Giam, K. K. The effect of arsenic on the dealloying of alpha-brass. J. Electrochem. Soc. 129, 2157-2163 (1982).

13. Cohen, A. Corrosion of Copper and Copper Alloys. In: ASM Handbook, Vol. $13 B$. Corrosion: Materials (eds Cramer, S. D. \& Covino, Jr B. S.) 125-163 (ASM Materials, 2005).

14. Rice, J. R. \& Wang, J.-S. Embrittlement of interfaces by solute segregation. Mat. Sci. Eng. A 107, 23-40 (1989).

15. National Research Council. Integrated Computational Materials Engineering: $A$ Transformational Discipline for Improved Competitiveness and National Security (The National Academies Press, Washington, DC, 2008) https://doi.org/10.17226/ 12199.

16. Sedriks, A. J. Corrosion of Stainless Steels. 2nd edn, (John Wiley \& Sons, 1996).

17. Cramer, S. D. \& Covine, Jr, B. S. (eds) ASM Handbook-Corrosion (ASM International 1998).

18. Kuehmann, C. J. \& Olson, G. B. Mater. Sci. Technol. 25, 472-478 (2009).

19. Krauss, G. Steels: Processing, Structure, and Performance (ASM International, Materials Park, OH, 2015).

20. National Research Council. Research Opportunities in Corrosion Science and Engineering (The National Academies Press, Washington, DC, 2011) https://doi. org/10.17226/13032.

21. Saal, J. E., Kirklin, S., Aykol, M., Meredig, B. \& Wolverton, C. Materials design and discovery with high-throughput density functional theory: the open quantum materials database (OQMD). Jom 65, 1501-1509 (2013).

22. Lorenz, K. \& Medawar, G. Über das Korrosionsverhalten austenitischer ChromNickel-(Molybd än-) Stähle mit und ohne Stickstoffzusatz unter besonderer Berücksichtigung ihrer Beanspruchbarkeit in chloridhaltigen Lösungen. Thyssenforschung 1, 97-108 (1969).

23. Jargelius-Pettersson, R. Application of the pitting resistance equivalent concept to some highly alloyed austenitic stainless steels. Corrosion 54, 162-168 (1998). 
24. Clayton, C. R. \& Olefjord, I. In: (ed. Marcus, P.) Corrosion Mechanisms in Theory and Practice 3rd edn, 327-347 (CRC Press, 2011).

25. de Borst, R. Challenges in computational materials science: multiple scales, multi-physics and evolving discontinuities. Comp. Mater. Sci. 43, 1-15 (2008).

26. Taylor, C. D. Corrosion informatics: an integrated approach to modelling corrosion. Corr. Eng. Sci. Tech. 50, 490-508 (2015).

27. Kuehmann, C. \& Olson, G. Computational materials design and engineering. Mater. Sci. Technol. 25, 472-478 (2009).

28. Lukas, H. L., Fries, S. G. \& Sundman, B. Computational Thermodynamics: The CALPHAD Method. Vol. 131 (Cambridge University Press, 2007).

29. Hafner, J., Wolverton, C. \& Ceder, G. Towards computational materials design: the impact of density functional theory on materials research. MRS Bull. 31, 659-668 (2006).

30. Holdren, J. P. Materials Genome Initiative for Global Competitiveness (National Science and Technology Council, Washington, DC, 2011).

31. Olson, G. B. Computational design of hierarchically structured materials. Science 277, 1237-1242 (1997).

32. Henkelman, G., Uberuaga, B. P. \& Jonsson, H. J. Chem. Phys. 113, 9901 (2000).

33. Mei, D., Xu, L. \& Henkelman, G. Dimer saddle point searches to determine the reactivity of formate on $\mathrm{Cu}(111)$. J. Catal. 258, 44-51 (2008).

34. Sun, G. \& Jiang, H. J. Chem. Phys. 143, 234706 (2015)

35. Marenich, A. V., Cramer, C. J. \& Truhlar, D. G. Universal solvation model based on solute electron density and on a continuum model of the solvent defined by the bulk dielectric constant and atomic surface tensions. J. Phys. Chem. B 113, 6378-6396 (2009).

36. Gartner, T. E., Epps, T. H. \& Jayaraman, A. J. Chem. Theory Comput. 12, 5501-5510 (2016).

37. Freysoldt, C. et al. Rev. Mod. Phys. 86, 253 (2014).

38. Taylor, C. D., Lookman, T. \& Lillard, R. S. Ab initio calculations of the uraniumhydrogen system: Thermodynamics, hydrogen saturation of $\mathrm{a}-\mathrm{U}$ and phase transformation to UH3. Acta Mat. 58, 1045-1055 (2010).

39. Norskov, J. K., Abild-Pederson, F., Studt, F. \& Bligaard, T. Density functional theory in surface chemistry and catalysis. Proc. Natl. Acad. Sci. 108, 937-943 (2010).

40. Murer, N., Oltra, R., Vuillemin, B. \& Neel, O. Numerical modelling of the galvanic coupling in aluminium alloys: A discussion on the application of local probe techniques. Corr. Sci. 52, 130-139 (2010).

41. DiCaprio, D. et al. Morphology of corroded surfaces: Contribution of cellular automaton modeling. Corr. Sci. 53, 418-425 (2011).

42. Wen, Y.-H., Chen, L.-Q. \& Hawk, J. A. Phase-field modeling of corrosion kinetics under dual oxidants. Model. Sim. Mat/s. Sci. Eng. 20, 035013 (2012).

43. Lin, L. F., Chao, C. Y. \& Macdonald, D. D. A point defect model for anodic passive films: II. Chemical breakdown and pit initiation. J. Electrochem. Soc. 128, 1194-1198 (1981)

44. Taylor, C. D. \& Liu, X.-Y. Investigation of structure and composition control over active dissolution of Fe-Tc binary metallic waste forms by off-lattice kinetic Monte Carlo simulations. J. Nuc. Mat. 434, 382-388 (2013).

45. Zhang, Yea Prog. Mat. Sci. 61, 1-93 (2014).

46. Boyer, J. A. The Corrosion of Magnesium and of the Magnesium Aluminum Alloys Containing Manganese. Report NACA-TR-248, (American Magnesium Corp, Cleveland, $\mathrm{OH}, 1927)$.

47. Hanawalt, J. D., Nelson, C. E. \& Peloubet, J. A. Corrosion studies of magnesium and its alloys. Trans. AIME 147, 273-299 (1942).

48. Simanjuntak, S. et al. The influence of iron, manganese, and zirconium on the corrosion of magnesium: an artificial neural network approach. Corrosion 71, 199-208 (2015).

49. Gandel, D. S., Easton, M. A., Gibson, M. A. \& Birbilis, N. Influence of Mn and Zr on the corrosion of Al-free $\mathrm{Mg}$ alloys: Part 2- Impact of $\mathrm{Mn}$ and $\mathrm{Zr}$ on $\mathrm{Mg}$ alloy electrochemistry and corrosion. Corrosion 69, 744-751 (2013).

50. Organ, L., Scully, J. R., Mikhailov, A. S. \& Hudson, J. L. A spatiotemporal model of interactions among metastable pits and the transition to pitting corrosion. Electrochim. Acta 51, 225-241 (2005).

51. Punckt, $C$. et al. Sudden onset of pitting corrosion on stainless steel as a critical phenomenon. Science 305, 1133-1136 (2004)

52. Scully, J. R., Budiansky, N. D., Tiwary, Y., Mikhailov, A. S. \& Hudson, J. L. An alternate explanation for the abrupt current increase at the pitting potential. Corros. Sci. 50, 316-324 (2008).

53. Rossi, M. L., Taylor, C. D. \& Van Duin, A. C. T. Reduced yield stress for zirconium exposed to iodine: reactive force field simulation. Adv. Model. Sim. Eng. Sci. 1, 19 (2015).

54. Sieradzki, K. \& Newman, R. C. J. Electrochem. Soc. 133, 1979-1980 (1986).

55. Erlebacher, J. An. Atomistic Description of dealloying: porosity evolution, the critical potential, and rate-limiting behavior. J. Electrochem. Soc. 151, C614-C626 (2004).
56. Artymowicz, D. M., Erlebacher, J. \& Newman, R. C. Relationship between the parting limit for de-alloying and a particular geometric high-density site percolation threshold. Philos. Mag. 89, 1663-1693 (2009).

57. Frankel, G. S., Newman, R. C., Jahnes, C. V. \& Russak, M. A. On the pitting resistance of sputter-deposited aluminum alloys. J. Electrochem. Soc. 140, 2192-2197 (1993)

58. Scully, J. R. Role of minor alloying elements in the corrosion of selected amorphous alloys. (National Science Foundation, 2009).

59. Huang, R., Horton, D. J., Bocher, F. \& Scully, J. R. Localized corrosion resistance of Fe-Cr-Mo-W-B-C bulk metallic glasses containing $\mathrm{mn}$ plus si or $\mathrm{y}$ in neutral and acidified chloride solutions. Corrosion 66 (2010).

60. Horton, D. J. \& Scully, J. R. The effect of the amorphous and crystalline states on preferential corrosion of $\mathrm{Hf}$ from a Cu75Hf20Dy05 alloy. Metall. Mater. Trans. A 43A, 2706-2720 (2012).

61. Gludovatz, B. et al. A fracture-resistant high-entropy alloy for cryogenic applications. Science 345, 1153-1158 (2014).

62. Yeh, J.-W. et al. Adv. Eng. Mater. 6, 299-303 (2004).

63. Tsai, M.-H. \& Yeh, J.-W. Mat. Res. Lett. 2, 107-123 (2014).

64. Galvele, J. R. Transport processes and mechanism of pitting of metals. J. Electrochem. Soc. 123, 464-474 (1976).

65. Beverskog, B. \& Puigdomenech, I. Pourbaix diagrams for the ternary system of iron-chromium-nickel. Corrosion 55, 1077-1087 (1999).

66. Calvo, E. J. The kinetics of oxygen electro-reduction: a long way from rust to $\mathrm{Li}$ air batteries. Mater. Corr. 65, 345 (2014).

67. Tang, Z., Huang, L., He, W. \& Liaw, P. K. Alloying and processing effects on the aqueous corrosion behavior of high-entropy alloys. Entropy-Switz. 16, 895-911 (2014).

68. Castle, J. E. \& Asami, K. A more general method for ranking the enrichment of alloying elements in passivation films. Surf. Interface Anal. 36, 220-224 (2004).

69. Kirchheim, R. et al. The passivity of iron-chromium alloys. Corros. Sci. 29, 899-917 (1989)

70. Wang, C. et al. Rational development of ternary alloy electrocatalysts. J. Phys. Chem. Lett. 3, 1668-1673 (2012).

71. Wang, C. et al. Correlation between surface chemistry and electrocatalytic properties of monodisperse PtxNi1-x nanoparticles. Adv. Funct. Mater. 21, 147-152 (2011).

72. Hausbrand, R., Stratmann, M. \& Rohwerder, M. Delamination resistant zinc alloys: simple concept and results on the system zinc-magnesium. Steel Res. Int. 74, 453-458 (2003)

73. Stratmann, M. 2005 W.R. Whitney Award Lecture: corrosion stability of polymercoated metals-new concepts based on fundamental understanding. Corrosion 61, 1115-1126 (2005)

74. Sato, N. Toward a more fundamental understanding of corrosion processes Corrosion 45, 354-368 (1989).

75. McCafferty, E. A surface charge model of corrosion pit initiation and of protection by surface alloying. J. Electrochem. Soc. 146, 2863 (1999).

76. McCafferty, E. Sequence of steps in the pitting of aluminum by chloride ions. $J$. Electrochem. Soc. 150, B342 (2003).

77. Shibata, T. Passivity breakdown and stress corrosion cracking of stainless steel. Corr. Sci. 49, 20-30 (2007).

78. Uberuaga, B. P., Andersson, D. A. \& Stanek, C. R. Defect behavior in oxides: insights from modern atomistic simulation methods. Curr. Opin. Solid State Mater. Sci. 17, 249-256 (2013).

79. Jiang, Y., Smith, J. R. \& Evans, A. G. Appl. Phys. Lett. 92, 141918 (2008).

80. Todorova, M. \& Neugebauer, J. Farad. Disc. 180, 97-112 (2015).

81. Sankaranarayanan, S. K. R. S. \& Ramanathan, S. Low temperature oxidation and ultrathin oxide growth on zirconium in the presence of atomic oxygen: a modeling study. J. Phys. Chem. C. 112, 17877-17882 (2008).

82. Newman, R. C. The dissolution and passivation kinetics of stainless alloys containing molybdenum .1. coulometric studies of fe-cr and fe-cr-mo alloys. Corros. Sci. 25, 331-339 (1985).

83. Marcus, P. On some fundamental factors in the effect of alloying elements on passivation of alloys. Corr. Sci. 36, 2155-2158 (1994).

84. Frankel, G. S., Stockert, L., Hunkeler, F. \& Boehni, H. Metastable pitting of stainless-steel. Corrosion 43, 429-436 (1987).

85. Frankel, G. et al. Localised corrosion: general discussion. Faraday Discuss. 180, 381-414 (2015).

86. Frankel, G. S., Scully, J. R. \& Jahnes, C. V. Repassivation of pits in aluminum thin films. J. Electrochem. Soc. 143, 1834-1840 (1996).

87. Anderko, A., Sridhar, N., Jakab, M. A. \& Tormoen, G. A general model for the repassivation potential as a function of multiple aqueous species. 2. effect of oxyanions on localized corrosion of Fe-Ni-Cr-Mo-W-N alloys. Corros. Sci. 50, 3629-3647 (2008).

88. Anderko, A., Sridhar, N., Brossia, C. S. \& Tormeon, G. NACE Corrosion 06215 (NACE International, 2006). 
89. Anderko, A., Gui, F., Cao, L. \& Sridhar, N. Corrosion 2014 TBD (NACE International, 2014).

90. Saal, J. E., Kirklin, S., Aykol, M., Meredig, B. \& Wolverton, C. Materials design and discovery with high-throughput density functional theory: the open quantum materials database (OQMD). JOM 65, 1501-1509 (2013).

91. Trasatti, S. Work function, electronegativity, and electrochemical behavior of metals. 3. electrolytic hydrogen evolution in acid solutions. J. Electroanal. Chem. 39, 163 (1972).

92. Seh, Z. W. et al. Combining theory and experiment in electrocatalysis: Insight into materials design. Science 355, 146 (2017).

93. Turnbull, A. Implications of internal cathodic reactions for crevice attack of stainless steels in chloride environments. Brit. Corr. J. 32, 283-290 (1997).

94. Turnbull, A. Prevention of crevice corrosion by coupling to more noble materials? Corros. Sci. 40, 843-845 (1998).

95. Mathew, K., Sundararaman, R., Letchworth-Weaver, K., Arias, T. A. \& Hennig, R. G. J. Chem. Phys. 140, 084106 (2014).

96. Letchworth-Weaver, K. \& Arias, T. A. Phys. Rev. B 86, 75140 (2012).

97. Pham, H. H., Taylor, C. D. \& Henson, N. J. Metal desorption from Fe(110) and its alloyed surfaces. Chem. Phys. Lett. 585, 162-166, https://doi.org/10.1016/j. cplett.2013.09.011 (2013).

98. Ashby, M. F. Materials Selection in Engineering Design. 4th edn, (ButterworthHeinemann, 2011).

99. Kittel, C. \& Holcomb, D. F. Introduction to solid state physics. Am. J. Phys. 35, 547-548 (1967).

100. Jain, A. et al. The materials project: a materials genome approach to accelerating materials innovation. APL Mater. 1, 011002 (2013).

101. Deltombe, E., de Zoubov, N. \& Pourbaix, M. Atlas of electrochemical equilibria in aqueous solution. (NACE, 1974).
102. Marcus, P. \& Grimal, J. M. The anodic-dissolution and passivation of $\mathrm{Ni}-\mathrm{Cr}-\mathrm{Fe}$ alloys studied by ESCA. Corros. Sci. 33, 805-814 (1992).

103. Seo, M. \& Sato, N. Theoretical approach to corrosion resistivity of alloys. Langmuir 3, 917-921 (1987)

104. Kirchheim, R. et al. The passivity of iron-chromium alloys. Corr. Sci. 29, 899-917 (1989).

105. Frankel, G. S. et al. Corrosion of glasses, ceramics and metals: a comparative review. npj Mat. Deg. (2018).

106. Frankel, G., Li, T. \& Scully, J. R. Perspective-localized corrosion: passive film breakdown vs pit growth stability. J. Electrochem. Soc. 164, C180-C181 (2017).

107. Mao, H., Chen, H.-L. \& Chen, Q. TCHEA1: a thermodynamic database not limited for high entropy alloys. J. Phase Eq. Diff. 38, 353-368 (2017).

(i) Open Access This article is licensed under a Creative Commons adaptation, distribution and reproduction in any medium or format, as long as you give appropriate credit to the original author(s) and the source, provide a link to the Creative Commons license, and indicate if changes were made. The images or other third party material in this article are included in the article's Creative Commons license, unless indicated otherwise in a credit line to the material. If material is not included in the article's Creative Commons license and your intended use is not permitted by statutory regulation or exceeds the permitted use, you will need to obtain permission directly from the copyright holder. To view a copy of this license, visit http://creativecommons. org/licenses/by/4.0/.

(c) The Author(s) 2018 